\title{
Dynamic kinetics of catalytic dehydrogenation of methanol to formaldehyde
}

\author{
Philippe Zaza, Harvey Randall, Ralf Doepper, Albert Renken* \\ Institute of Chemical Engineering. Swiss Federal Institute of Technology, CH-1015 Lausanne, Switzerland
}

\begin{abstract}
Methanol dehydrogenation to formaldehyde was operated in a continuous fixed-bed reactor with external recycling in the presence of sodium carbonate catalyst supported on active carbon. Due to the importance of gas phase decompositions of methanol and mainly formaldehyde, selectivity of formaldehyde in such a reactor is small compared to that obtained in a fixed-bed reactor. Furthermore, the contribution of gas phase reactions to formaldehyde synthesis through global dehydrogenation of methanol complicates steady-state kinetic studies. However, transient and methanol isotope $\left(\mathrm{CD}_{3} \mathrm{OD}\right.$ and $\mathrm{CH}_{3} \mathrm{OD}$ ) transient experiments showed that a hydrogen species and also a methoxy and/or a hydroxymethyl intermediate( $\mathrm{s}$ ) are strongly adsorbed on the catalyst surface. Based on these facts, a mechanism of methanol dehydrogenation on sodium carbonate catalyst supported on active carbon is proposed.
\end{abstract}

\section{Introduction}

Formaldehyde is commercially manufactured by the oxidation of methanol in the presence of iron-molybdenum-vanadium oxide or a silver catalyst $[1,2]$, producing an aqueous solution. Pure formaldehyde is obtained by separation processes such as distillation, which is difficult and expensive due to negative deviations from ideal solution behaviour and the formation of azeotropes [3]. An attractive alternative to the current method is the catalytic methanol dehydrogenation to produce water-free formaldehyde:

$$
\mathrm{CH}_{3} \mathrm{OH} \longleftrightarrow \mathrm{CH}_{2} \mathrm{O}+\mathrm{H}_{2} \quad \Delta H_{r, 300 \mathrm{~K}}=85 \mathrm{~kJ} \mathrm{~mol}^{-1}
$$

This reaction is thermodynamically reversible in the temperature range of concern, according to calculations with the data of Daubert and Danner [4]. In order to produce pure formaldehyde without a unit operation of separation a high conversion of methanol is

\footnotetext{
${ }^{*}$ Corresponding author.
} 


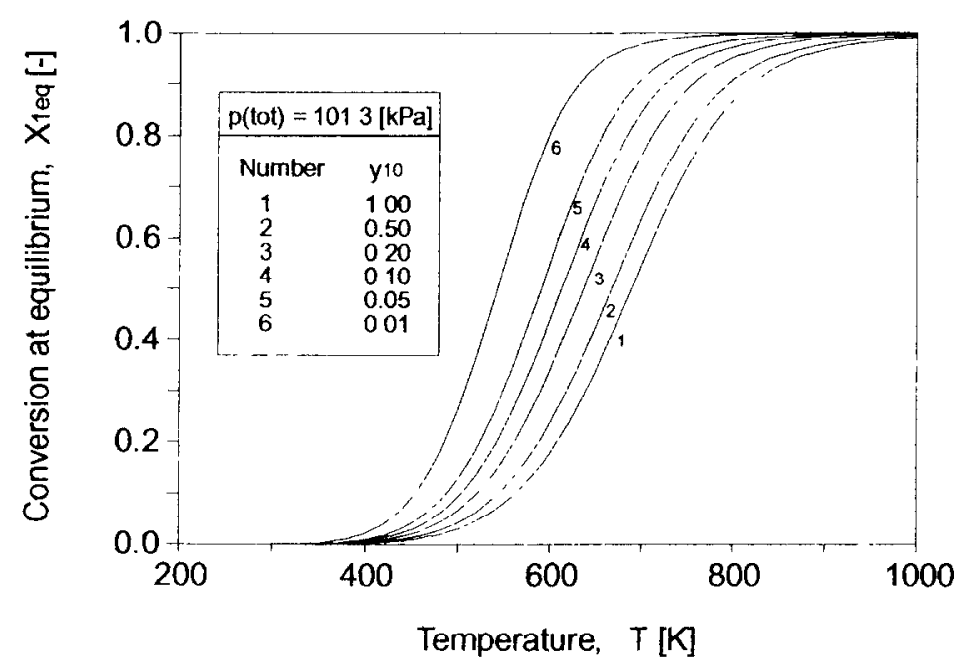

Fig. 1. Methanol conversion $X_{\text {Ieq }}$ at equilibrium vs temperature $T$ and initial molar fraction $v_{1}$ of methanol at a total pressure of $1013 \mathrm{kPa}$.

desired. Fig. 1 shows methanol conversion $X_{\mathrm{leq}}$ at equilibrium as a function of temperature and of dilution with an inert at a total pressure of $101.3 \mathrm{kPa}$. For instance, with an initial molar fraction of methanol $y_{10}=0.1$, the conversion reaches $99 \%$ when temperature exceeds $870 \mathrm{~K}$.

Many materials which are described in refs. [5-8] were found to exhibit catalytic activity for the dehydrogenation of methanol. Among them, sodium carbonate [9,10], mixed lithium and sodium aluminate [11] and sodium carbonate mixed with or supported on active carbon $[7,12]$ were shown to exhibit high activity, high selectivity for formaldehyde and good stability at around $970 \mathrm{~K}$ (carbonate) and $1170 \mathrm{~K}$ (alumınate).

The three catalysts were studied in a continuous fixed-bed reactor with external recycling. Due to the importance of gas phase decompositions of methanol and formaldehyde, the temperature range was limited between 873 and $973 \mathrm{~K}$. At these temperatures, carbonate catalysts showed higher formaldehyde selectivity than aluminate. Furthermore, when active carbon is mixed with or supports sodium carbonate [12], it enhances drastically the activity of the catalyst without modifying its selectivity for formaldehyde. A mechanism of the promoting effect is suggested by Su et al. [12], which involves hydrogen spillover. So research described in the present paper is focused on the sodium catalyst supported on active carbon.

However, with this catalyst, carbon monoxide, methane, and trace amounts of carbon dioxıde, water and coke are also produced as side products. Therefore, it is useful to identify the reaction mechanism to provide guidance for limiting side reactions and increasing the activity of the catalyst. Transient and methanol isotope transient experiments were used in order to reach that goal. 


\section{Experimental}

\subsection{Catalyst preparation and characterization}

The catalyst was prepared by fluidising activated charcoal (35-50 mesh ASTM, art. 9631 , Merck, Darmstadt, D) in an aqueous solution of sodium carbonate ( $>99 \%$ pure, art. 71351, Fluka, Buchs, $\mathrm{CH}$ ). Using an atomic absorption spectrophotometer (model 1100 , Perkin-Elmer Ltd., Beaconsfield, GB), the amount of sodium supported was determined: $0.1 \mathrm{~g} \mathrm{(Na)} / \mathrm{g}$ (catalyst). Laser $\mathrm{He} / \mathrm{Ne}$ diffraction (droplet and particle sizer, series $2600 \mathrm{C}$, Malvern Instruments, Malvern, GB) gave a mean particle size of $450 \mu \mathrm{m}$. Such a catalyst has a specific area of $1040 \mathrm{~m}^{2} \mathrm{~g}^{-1}$ (Sorpty 1750 , Carlo Erba Instruments, Milano, I) which is slightly less than the specific area of pure active carbon $\left(1122 \mathrm{~m}^{2} \mathrm{~g}^{-1}\right)$.

\subsection{Apparatus}

The experimental set-up is shown in Fig. 2. This equipment is composed of three different parts: feed, reaction and analysis, and is described in detail elsewhere [13]. The feed consists of pure gases ( $>99.99 \%$, Carbagas, Lausanne, $\mathrm{CH}$ ) or mixture of gases whose flow rates are set by mass flow controllers (type 5878, Brooks Instrument BV, Veenendaal, NL). It also includes two different temperature-controlled bubble columns fed by a carrier gas (argon) for mcthanol (99.9\%, No. 1230, Romil Chcmicals Ltd., Langhborough, GB) and tetradeuterated $\mathrm{CD}_{3} \mathrm{OD}$ ( $>99.5$ atom\% D, No. 45416, Dr. Glaser AG, Basel, $\mathrm{CH}$ ) or monodeuterated $\mathrm{CH}_{3} \mathrm{OD}$ ( > 99.9 atom\% D, No. 57923, Dr. Glaser AG, Basel, $\mathrm{CH}$ ) meth-

$\begin{array}{lll}\text { FEED REACTION ANALYSIS } & \end{array}$

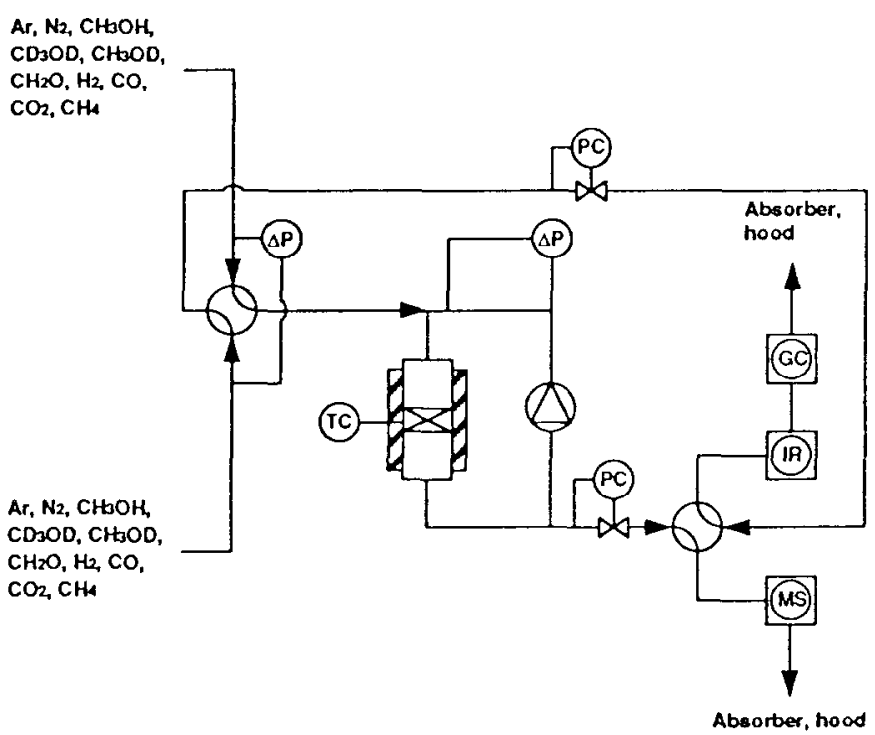

Fig. 2. Schematic layout of experimental apparatus. 
anol, and a temperature-controlled device filled with paraformaldehyde (art. 4005, Merck, Darmstadt, D) producing formaldehyde vapor.

The reaction was operated at a pressure of $150 \mathrm{kPa}$ in a continuous fixed-bed reactor (quartz tube, internal diameter $=10 \mathrm{~mm}$ ) with an external recycle loop. Reaction zone was heated by a temperature-controlled electric oven ( $\mathrm{RO} 4 / 25$, Heraeus AG, Zürich, CH) and recycling was ensured by a diaphragm compressor (N026AT11E, KNF Neuberger GmbH, Freiburg-Munzingen, D). A movable thermocouple protected in a quartz sleeve was located inside the reaction zone in which the catalyst $(0.1 \mathrm{~g})$ was held in place by two layers of quartz wool. The residence time distribution (RTD) in such a reactor was determined by step experiments of an inert gas (nitrogen in argon). For instance, at $923 \mathrm{~K}$ and with a total flow-rate of $2 \mathrm{ml} \mathrm{s}^{-1}$ at standard temperature and pressure (STP), the residence time $\tau$ is $36 \mathrm{~s}$, the recycle ratio about 80 and the reactor behaves hydrodynamically as a continuous stirred tank reactor.

The reactor effluent was analysed with a gas chromatograph (GC) (model 5340, Carlo Frba Instruments, Milano, I) equipped with a thermal conductivity detector and a $50 \mathrm{~cm} \times 1 /$ 8 in. stainless steel column filled with Carbosieve S 120-140 mesh and with an infra-red spectrophotometer (IR) (model 781, Perkin-Elmer Ltd., Beaconsfield, GB). Furthermore, effluent was continuously analysed during transient experiments using a mass spectrometer (MS) (type QMG420, Balzers AG, Balzers, FL).

\section{Results}

\subsection{Steady-state methanol dehydrogenation and gas phase reactions}

Methanol dehydrogenation operated with $0.1 \mathrm{~g}$ carbonate sodium catalyst supported on active carbon in the recycle reactor leads to low formaldehyde selectivities. For instance, at $923 \mathrm{~K}$ using a $3 \%$ methanol feed $\left(\tau=36 \mathrm{~s}\right.$, total flow-rate $=2 \mathrm{ml} \mathrm{s}^{-1}(\mathrm{STP}), p=150 \mathrm{kPa}$ ) formaldehyde selectivity is 0.4 , whereas it reaches 0.9 in a fixed-bed reactor ( $\tau=1 \mathrm{~s}, p=101$ $\mathrm{kPa}$ ) (Fig. 3). 'This is mainly due to the importance of the consecutive thermal decomposition of formaldehyde in the recycle reactor.

Substituting the catalyst by quartz wool, formaldehyde and methanol thermal decompositions were carried out in the continuous recycle fixed-bed reactor. The products of formaldehyde pyrolysis are almost exclusively carbon monoxide and hydrogen. For instance, at $923 \mathrm{~K}$ using a $1 \%$ formaldehyde feed $\left(\tau=36 \mathrm{~s}\right.$, total flow-rate $=2 \mathrm{ml} \mathrm{s}^{-1}$ ( STP), $p=150$ $\mathrm{kPa}$ ), formaldehyde conversion reaches 0.6 . Traces of methanol are also detected at temperatures below $873 \mathrm{~K}$, which is in agreement with other works [14,15]. According to several authors [16-18], it is generally accepted that formaldehyde decomposition is a chain reaction involving $\mathrm{H}$ radicals, which are important in the propagation step.

Methanol thermal decomposition is less important. For instance, at $923 \mathrm{~K}$ using a $3 \%$ methanol feed ( $\tau=36 \mathrm{~s}$, total flow-rate $=2 \mathrm{ml} \mathrm{s}^{-1}$ (STP), $p=150 \mathrm{kPa}$ ), methanol conversion is less than 0.1 . It produces mainly carbon monoxide and hydrogen, small amounts of methane, formaldehyde and water, and traces of carbon dioxide. As methanol is considered to be an alternative fuel for gasoline and as the initiation step in its high-temperature oxidation is its thermal decomposition, the mechanism of methanol pyrolysis has been 


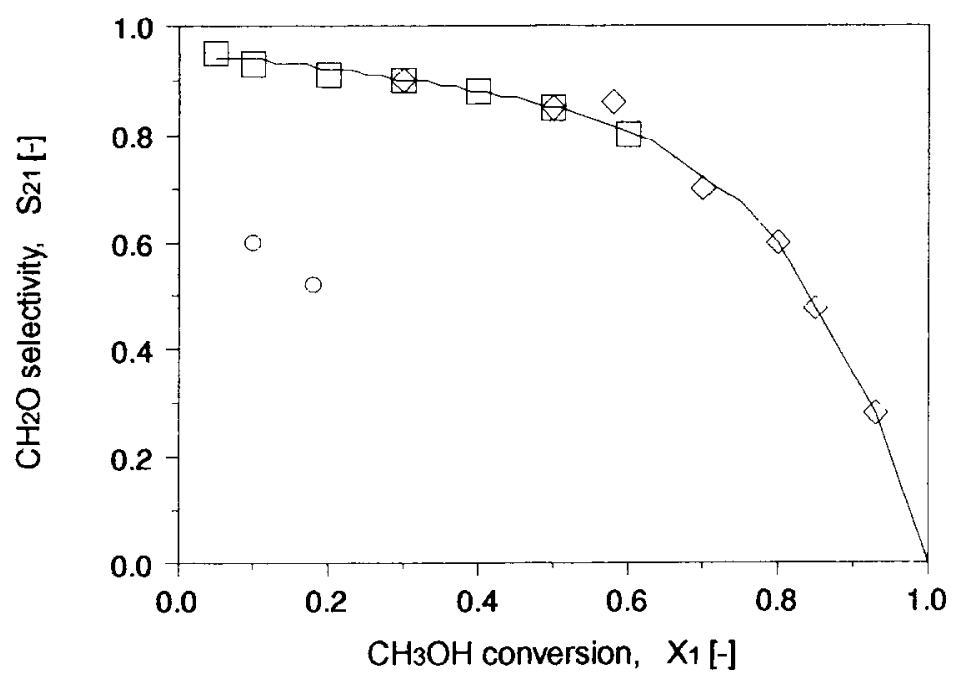

Fig. 3. Formaldehyde selectivity $S_{21}$ vs. methanol conversion $X_{1}$ for different catalysts in a fixed-bed reactor [ 12 ]. Conditions: $01 \mathrm{~g}$ catalyst, $\tau=1 \mathrm{~s}, y_{10}=0.05$, total flow-rate $=3.3 \mathrm{ml} \mathrm{s}^{-1}$ (STP), $p=101 \mathrm{kPa}, T=963 \mathrm{~K}$. Catalyst: (口) $\mathrm{Na}_{2} \mathrm{CO}_{3},(\diamond) \mathrm{Na}_{2} \mathrm{CO}_{3}$ and active carbon, (O) active carbon.

subjected to many investigations. Methanol decomposition is a complex chain reaction involving ${ }^{\circ} \mathrm{CH}_{2} \mathrm{OH},{ }^{\prime} \mathrm{CH}_{3}, \mathrm{CH}_{3} \mathrm{O},{ }^{\prime} \mathrm{H}$ and ${ }^{\prime} \mathrm{CHO}$ radicals [ 19-21].

Gas phase reactions also contribute to the formation of formaldehyde in the overall methanol dehydrogenation reaction. According to Su et al. [10], experiments performed in a specially designed fixed-bed reactor show that about half of the methanol conversion takes place in the post-catalytic space, where the formaldehyde selectivity is in the same range as for the catalytic reaction. So the global dehydrogenation reaction occurring in the recycle reactor may be schematised as follows:

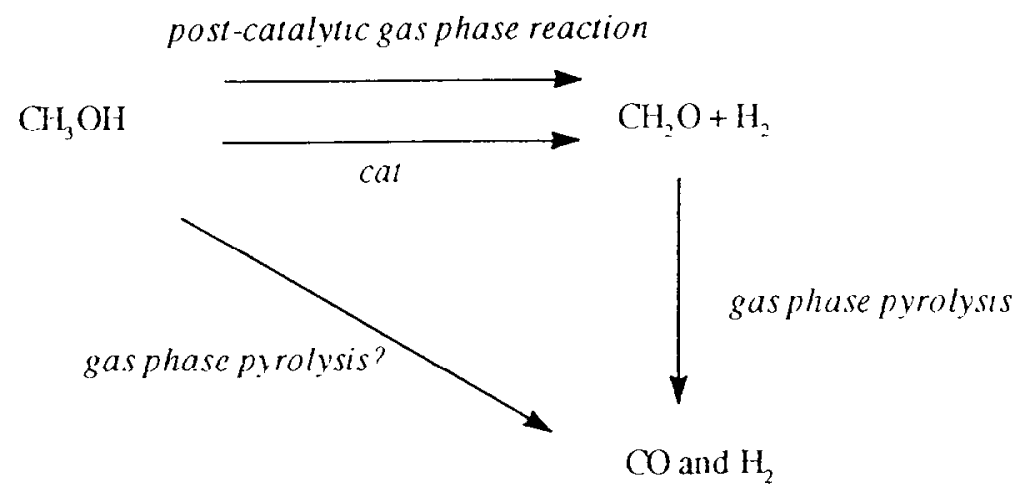

\subsection{Transient experiments}

Although catalysis can be understood through steady-state experiments, transient experiments usually provide additional information. Often steady-state data can be explained by 


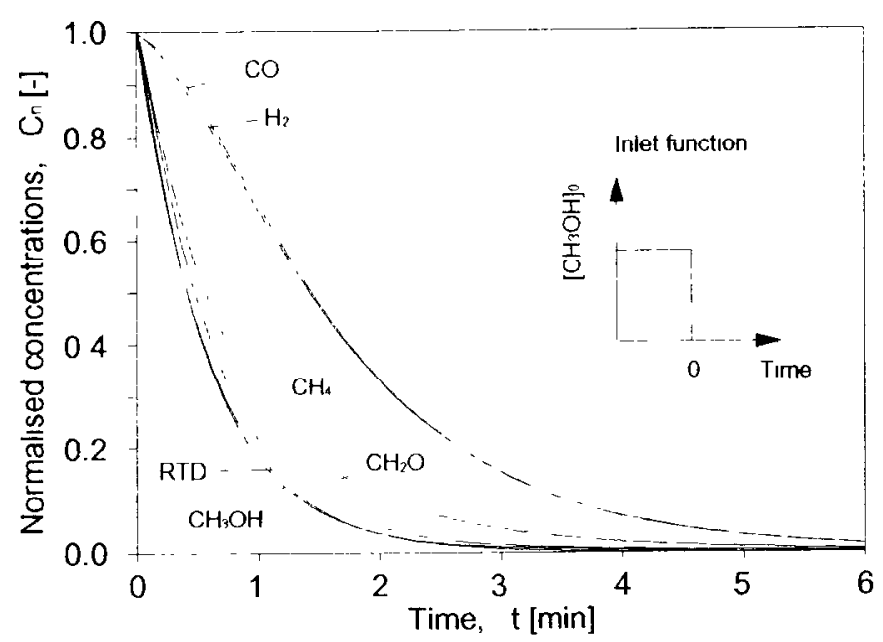

Fig 4. Step-down response curves to an interruption of the $1 \%$ methanol feed Conditions: $01 \mathrm{~g} \mathrm{Na}_{2} \mathrm{CO}_{3} / \mathrm{C}$, $\tau=36 \mathrm{~s}$, total flow-rate $=2 \mathrm{ml} \mathrm{s}^{-1}(\mathrm{STP}), p=150 \mathrm{kPa}, T=923 \mathrm{~K}$.

numerous different models, whereas the simulation of transient experiments usually requires the use of a detailed, complex model. Therefore, the transient behaviour of a catalytic reaction gives a better insight into the reaction mechanism. This can be illustrated by the following measurements of methanol dehydrogenation.

Interesting, results were obtained by step-down experiments which are the response to an interruption of the methanol feed. Such an experiment is presented in Fig. 4 and was performed as follows: methanol dehydrogenation operating in the recycle reactor was first stabilised at $923 \mathrm{~K}$ and $150 \mathrm{kPa}$ using $0.1 \mathrm{~g}$ of sodium carbonate catalyst supported on active carbon and a feed of $1 \%$ methanol in argon and then, at $t=0$, the feed was switched to the same flow-rate as pure argon. In Fig. 4, the changes in gas phase concentrations (normalised to their steady-state values) indicate that:

(1) methanol and formaldehyde almost follow RTD,

(2) methane is delayed,

(3) carbon monoxide and hydrogen are considerably delayed and are still present in the reactor effluent after the total disappearance of methanol and formaldehyde.

So, either these latter species are strongly adsorbed on the catalyst surface or are produced by a strongly adsorbed intermediate.

Desorption experiments performed by respectively adsorbing methane, carbon monoxide and hydrogen on the catalyst and then switching to pure argon were carried out at the same conditions as for the step-down experiment. If desorption compared to the step-down experiment explains the delay of methane, an important difference is noticed for hydrogen and carbon monoxide. For hydrogen, this may result from differences in adsorption modes, i.e., molecular sorption during the desorption experiment, and dissociative adsorption of methanol producing atomic hydrogen during the step-down experiment. However, the different carbon monoxide responses to the step-down and the desorption experiments (Fig. 5) seem to confirm the existence of a strongly adsorbed intermediate (probably a methoxy or a hydroxymethyl species) producing carbon monoxide and hydrogen. 


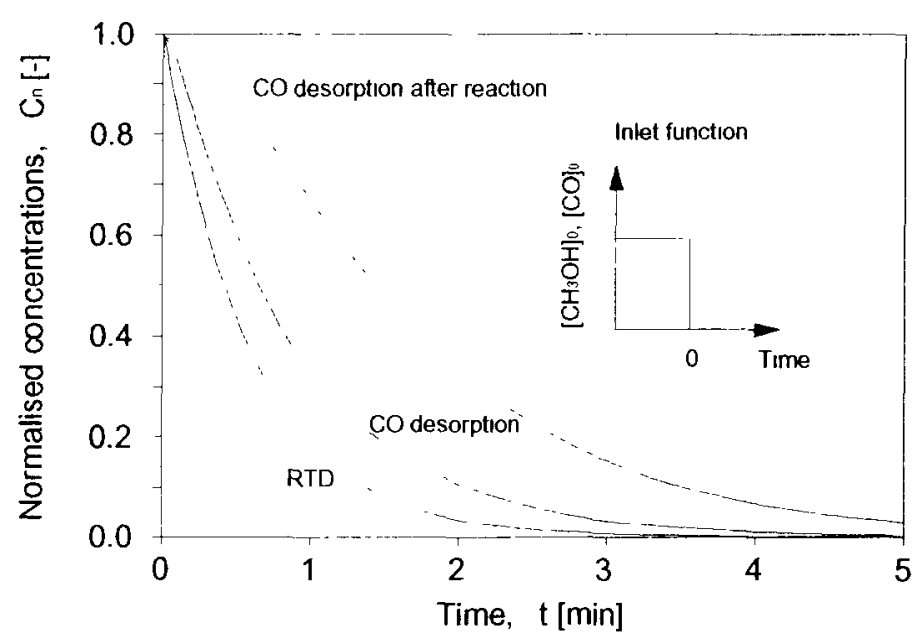

Fig. 5. Step-down and desorption response curves to an interruption of the $1 \%$ methanol or carbon monoxide feed. Conditions: $0.1 \mathrm{~g} \mathrm{Na}_{2} \mathrm{CO}_{3} / \mathrm{C}, \tau=36 \mathrm{~s}$, total flow-rate $=2 \mathrm{ml} \mathrm{s}^{-1}$ (STP), $p=150 \mathrm{kPa}, T=923 \mathrm{~K}$.

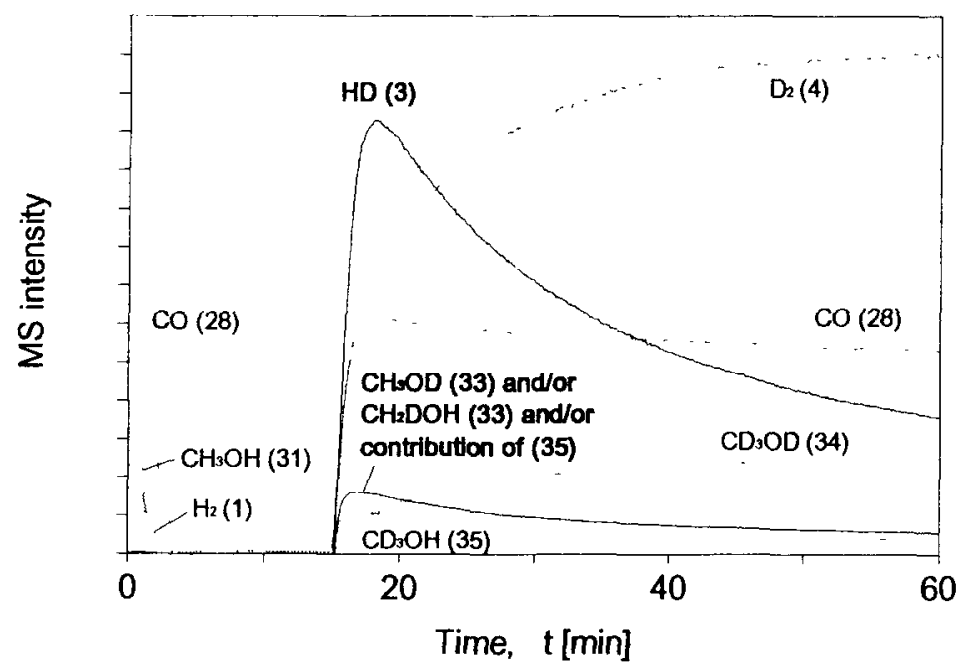

Fig. 6. Continuous mass spectrometer signals of reactor effluent. The recycle reactor was initially stable in $1 \%$ $\mathrm{CH}_{3} \mathrm{OH}$, then, at $t=1 \mathrm{~min}$, the fecd was switched to $\mathrm{Ar}$ and changed to $1 \% \mathrm{CD}_{3} \mathrm{OD}$ at $t=15 \mathrm{~min}$. Conditions: 0.1 $\mathrm{g} \mathrm{Na}_{2} \mathrm{CO}_{3} / \mathrm{C}, \tau=36 \mathrm{~s}$, total flow-rate $=2 \mathrm{ml} \mathrm{s}^{-1}$ (STP), $p=150 \mathrm{kPa}, T=923 \mathrm{~K}$.

\subsection{Transient methanol isotope experiments}

In order to prove the presence of a strongly adsorbed intermediate, transient methanol isotope experiments were performed using $\mathrm{CD}_{3} \mathrm{OD}$ and $\mathrm{CH}_{3} \mathrm{OD}$. Fig. 6 and Fig. 7 present mass spectrometer signals observed for the effluent of a dynamically operated continuous recycle reactor for methanol dehydrogenation using $0.1 \mathrm{~g}$ of sodium carbonate catalyst supported on active carbon at $923 \mathrm{~K}$ and $150 \mathrm{kPa}$. The experiments were performed as follows: 


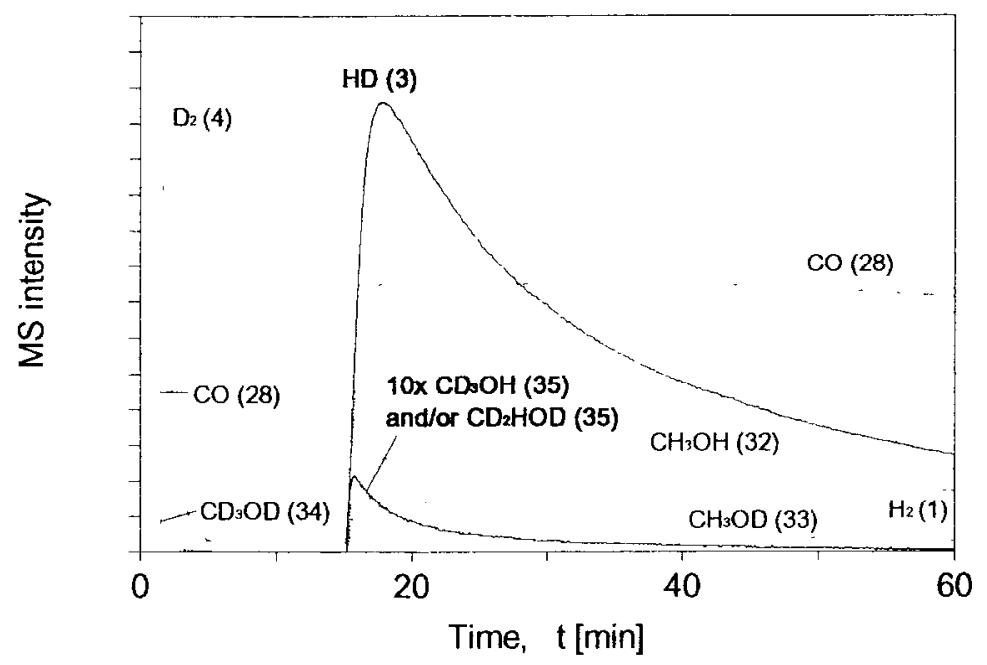

Fig. 7. Continuous mass spectrometer signals of reactor effuent. The recycle reactor was initially stable in $1 \%$ $\mathrm{CD}_{3} \mathrm{OD}$, then, at $t=1 \mathrm{~min}$, the feed was switched to $\mathrm{Ar}$ and changed to $1 \% \mathrm{CH}_{3} \mathrm{OH}$ at $t=15$ min Conditions: 0.1 $\mathrm{g} \mathrm{Na}_{2} \mathrm{CO}_{3} / \mathrm{C}, \tau=36 \mathrm{~s}$, total flow-rate $=2 \mathrm{ml} \mathrm{s}^{-1}(\mathrm{STP}), p=150 \mathrm{kPa}, T=923 \mathrm{~K}$.

(1) The reactor was first stabilised with $1 \%$ methanol in argon and then switched at $t=1$ min to the same flow-rate as pure argon; next, at $t=15 \mathrm{~min}$, the feed was switched to $1 \%$ $\mathrm{CD}_{3} \mathrm{OD}$ in argon (Fig. 6).

(2) The reactor was first stabilised with $1 \% \mathrm{CD}_{3} \mathrm{OD}$ in argon and then switched at $t=1$ min to pure argon; at $t=15 \mathrm{~min}$, the feed was switched to $1 \%$ methanol in argon (Fig. 7).

A large peak of HD ( specific mass $=3 \mathrm{amu}$ ) is observed in both experiments. This shows that hydrogen and deuterium are stored on the catalyst and that they desorb very slowly. They are still present in large amounts on the catalyst surface after a 14-min argon purge. So, the overall rate of methanol dehydrogenation is certainly determined by hydrogen recombination and desorption from the catalyst surface. Other data not shown resulting from $\mathrm{CH}_{3} \mathrm{OD}$ experiments indicate that the stored hydrogen originates from both the hydroxyl and methyl groups of the methanol.

In the first experiment, a peak of $\mathrm{CH}_{3} \mathrm{OD}$ and/or $\mathrm{CH}_{2} \mathrm{DOH}$ (specific mass $=33 \mathrm{amu}$ ) is detected. However, this peak cannot be attributed with certainty to surface $\mathrm{CH}_{3} \mathrm{O}$ and/or $\mathrm{CH}_{2} \mathrm{OH}$ species, as the contribution of $\mathrm{CD}_{3} \mathrm{OH}$ ( specific mass $=35 \mathrm{amu}$ ) may also produce a signal at $33 \mathrm{amu}$. The reverse experiment (Fig. 7) was performed in order to avoid this problem. A small peak of $\mathrm{CD}_{3} \mathrm{OH}$ and/or $\mathrm{CD}_{2} \mathrm{HOD}$ (specific mass $=35 \mathrm{amu}$ ) is detected showing that methoxy and/or hydroxymethyl species exist on the catalyst surface and desorb slowly.

\section{Discussion}

Based on the results of transient experiments and of Su et al. [10,12], a mechanism for methanol dehydrogenation to formaldehyde on sodium carbonate and sodium carbonate 
Table 1

Proposed mechanisms for methanol dehydrogenation to formaldehyde on $\mathrm{Na}_{2} \mathrm{CO}_{3}$ and $\mathrm{Na}_{2} \mathrm{CO}_{3}$ mixed with or supported on active carbon catalysts where ' $\mathrm{s}$ ', ' $\mathrm{g}$ ' and ' $c$ ' subscripts indicate respectively sodium carbonate surface, gas phase and carbon surface

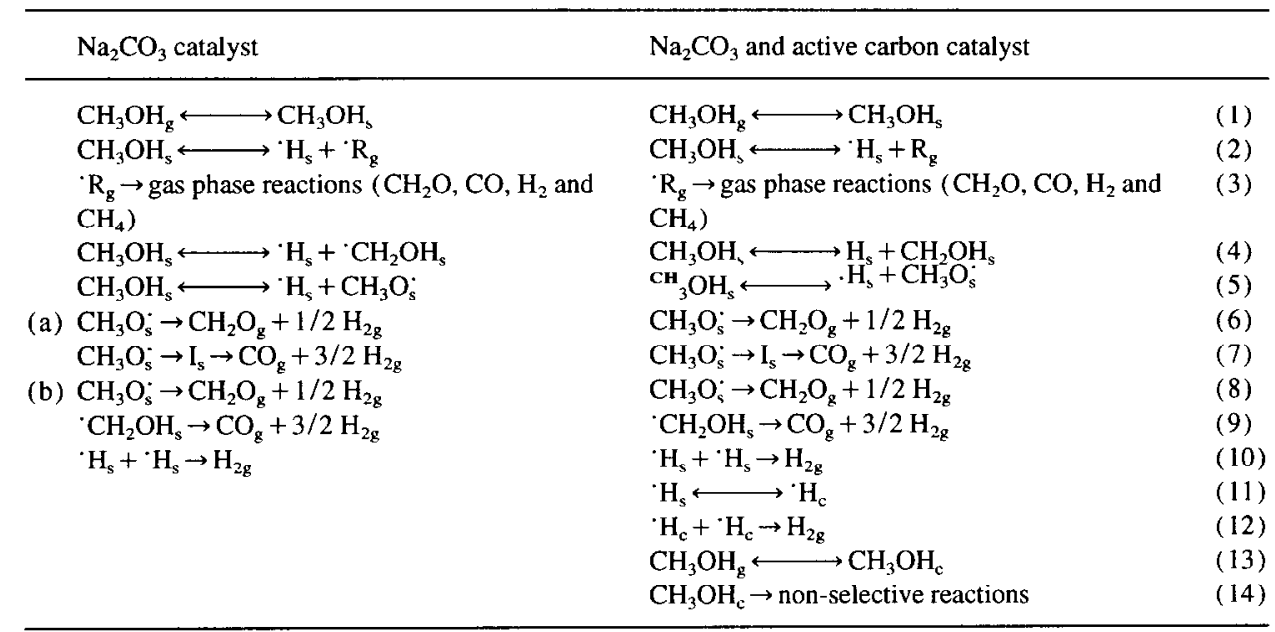

plus active carbon catalysts is proposed in Table 1 where ' $\mathrm{s}$ ', ' $\mathrm{g}$ ' and ' $\mathrm{c}$ ' subscripts indicate respectively sodium carbonate surface, gas phase and active carbon surface.

The first step is methanol adsorption on sodium carbonate. As mentioned previously [10], an important part of methanol dehydrogenation occurs in the gas phase. So, chemisorbed methanol is dissociated on the sodium carbonate surface into adsorbed hydrogen and a gas phase radical ${ }^{\prime} R_{g}(\operatorname{step} 2)$. This radical initiates a series of homogeneous reactions (step 3 ) that result in the final reaction products. Transient methanol isotope experiments have proved the existence of an adsorbed intermediate which may be a hydroxymethyl and/ or a methoxy species formed by steps 4 and 5 .

Two possibilities that account for the direct formation of formaldehyde and carbon monoxide on the sodium carbonate surface are presented ( $a$ and $b$ ) in Table 1. The first possibility is that the methoxy species forms formaldehyde and carbon monoxide, via parallel reactions (steps 6 and 7). Reaction 6 must be faster than reaction 7 in order to account for the high formaldehyde selectivity measured in a fixed-bed reactor $[10,12]$. This methoxy intermediate cannot be the strongly adsorbed intermediate observed during transient experiments, because, if this was the case, the formaldehyde signal would also be delayed during the step-down experiment. So, reaction 7 which is not an elementary step may pass through a strongly adsorbed intermediate $I_{s}$, the one detected during transient experiments. The second possibility assumes the presence of two sodium carbonate surface intermediates: a weakly adsorbed species (probably a methoxy) mainly producing formaldehyde (step 8 ) and a strongly adsorbed species (probably a hydroxymethyl) principally producing carbon monoxide ( step 9).

Recombination and desorption of adsorbed hydrogen (step 10) is the rate controllingstep as obscrved during the transient methanol isotope experiments. All steps mentioned until now take place in the presence of sodium carbonate alone, i.e., on the sodium carbonate 
surface and in the gas phase. A several-fold increase of activity without changing formaldehyde selectivity is observed when sodium carbonate is mixed with or supported on active carbon $[7,12]$. This suggests that atomic hydrogen produced on sodium carbonate spills over onto active carbon ( step 11) and recombines to form hydrogen gas (12). This surface diffusion process accelerates hydrogen desorption from sodium carbonate (step 10), the rate-controlling step. Finally, methanol adsorption on the active carbon surface (step 13) is less important and leads to non-selective reactions (14).

\section{Acknowledgements}

Financial support by the Swiss National Science Foundation is gratefully acknowledged.

\section{References}

[1] G Reuss. W. Disteldorf, O Grundler and A. Hilt, Formaldehyde in Ullmann's of Encyclopedia Industrial Chemistry, 5th ed., Vol. All, vCH, Weinheim, 1988, p. 619.

[2] J Catalán-Cancho, A.M Estévez-Sánchez, A. Fernández-Tena and M.C. Márquez-Moreno, Chem. Biochem. Eng. Quarterly, 3 (1989) 51.

[3] S. Brandani, V. Brandani and G. Di Gracomo, Ind. Eng Chem. Res., 31 (1992) 1792

[4] T.E. Daubert and R.P. Danner, Physical and Thermodynamic Properties of Pure Chemicals: Data Compilation, Hemısphere Publishing Corp., New York, 1989.

[5] A. Meyer, Ph.D. Thesis, No. 759, Swiss Federal Institute of Technology, Lausanne, 1988

[6] G. Wiesgickl, Ph.D. Thesis, Friednch-Alexander-Universitat, Erlangen-Nürnberg, 1989.

[7] S. Su, Ph.D. Thesis, No. 970, Swiss Federal Institute of Technology, Lausanne, 1991.

[8] S. Su, Ph. Zaza, and A. Renken, Chem Eng. Technol., submitted.

[9] A. Meyer and A. Renken, Chem Eng. Technol., 19 (1990) 145.

[10] S. Su, M.R Prairie and A Renken, Appl. Catal. A: General, 91 (1992) 131.

[11] G Wiesgickl. H Beck and G. Emıg, Appl. Catal., 59 (1990) Ll.

[12] S. Su, M.R. Prairie and A. Renken, Appl Catal A: General, 95 (1993) 131.

[13] Ph Zaza, Ph D Thesis, in preparatıon.

[14] J E. Longfield and W D. Walters, J. Am Chem. Soc., 77 (1955) 6098.

[15] C.J. Chen and D.J. McKenney, Can. J Chem, 50 (1972) 992

[16] H.G. Schecker and W Jost. Ber. Bunsenges. Physik. Chem . 73 (1969) 521

[17] K. Tadasa, N. Imai and T. Inaba, Bull. Chem. Soc. Jpn., 47 ( 1974) 548.

[18] L. Batt, G. Alvardo-Salinas and I.A.B. Reid, Int. Symp. on Combustion. The Combustion Institute, 1982, p 81

| 19| D Aronowitz, D.W. Naegelı and I. Glassman, J. Phys. Chem, 81 (1977) 2555.

|20| M. Cathonnet, J -C. Boettner and H James, de Chım. Phys, 76 (1979) 985.

[21] Norton, T.S. F.L Dryer, Toward a comprehensive mechanism for methanol pyrolysis, Int J Chem Kin, $22(1990) 219$. 